In: SILVEIRA, Paula Lemos (Org.). O ensino em contexto pandêmico [livro eletrônico]. São Paulo: Vecher, 2021. Disponível em: <https://doi.org/10.47585/9786599324239>.

\title{
Aula particular em tempo de pandemia: alfabetização
}

\author{
Patrícia Ribeiro ${ }^{1}$ e Maria Helena Silva ${ }^{2}$
}

doi.org/10.47585/9786599324239.4

Este capítulo tem como base a execução de aulas particulares na cidade de Dom Pedrito, Rio Grande do Sul, durante a pandemia decorrente do Covid-19. As aulas particulares/ reforço-escolar sempre fizeram parte do ambiente escolar, pois as mesmas conseguem tornar os alunos mais confiáveis em seus afazeres e terem domínio de assuntos que antes não conseguiam, as dificuldades de aprendizagem são trabalhadas de forma que os alunos venham a superá-las. Neste momento pandemico, não é diferente. As aulas particulares continuam com sua devida importância na vida escolar do aluno, porém a procura se tornou maior e com mais urgência, pois não se tornaram somente o apoio de alunos, mas também apoio dos pais, as justificativas dos mesmos são: seus filhos não aprenderem o conteúdo no formato remoto com vídeo-aulas, falta de tempo para acompanhar as atividades escolares e despreparo no sentido pedagógico, para ensinar a prole.

Palavras-chave: Educação; Alfabetização; Aula Particular; Reforço-escolar; Pandemia.

1 Graduada em Pedagogia pelo Centro Universitário da Regiãoda Campanha - Urcamp.Especialista em Neuropsicopedagogia pelo Instituto Educar Brasil. http://lattes.cnpq.br/9015520355090013. E-mail: patriciaribeiro-1993@hotmail.com.

2 Graduada em Pedagogia pelo Centro Universitário da Região da Campanha-Urcamp. Especialista em Neuropsicopedagogia pelo Instituto Educar Brasil. http://lattes.cnpq.br/9576401419607469. E-mail: helenaribeiro-ribeiro@hotmail.com. 


\section{Introdução}

Desde o inicio da pandemia do coronavírus, a rede de educação de Dom Pedrito, Rio Grande do Sul, se adaptou à realidade de ensino remoto. Gestores, professores, alunos e pais passaram a acompanhar o andamento da educação, cada um na sua casa. Com tal mudança, todos ficaram surpresos, as escolas de imediato fizeram uma pequena pausa, todos previam que logo voltaria a normal, mas para a preocupação de todos, o vírus pegou força e as escolas e professores tiveram que se reinventar para assim seguir com o ano letivo. Utilizando plataformas de ensino como o Classroom, Google Meet e grupos de Whatsapp para manter contato e enviar tarefas, os docentes aproveitaram as ferramentas disponíveis para estarem mais próximos do aluno. Porém, houve bastante dificuldade, tanto por parte do professor quanto do aluno, muitos não tinham acesso à internet, não tinham computador e os pais não sabiam lidar com tal tecnologia pedida no momento. Então, desta forma, os pais procuraram o apoio de professores particulares para que houvesse um acompanhamento mais concreto, onde seus filhos pudessem ter um reforço para o ensino remoto, como medida para melhorar o aprendizado dos mesmos. Desta forma, as aulas particulares passaram a ser alternativas em meio às incertezas de volta das escolas.

Por vezes, durante as aulas neste modelo remoto, o profesor não consegue passar muitas atividades diferentes ou até variá-las. Afinal, o conteúdo é muito extenso e há pouco tempo para desenvolver, por isso durante as aulas particulares é possível o professor utilizar atividades mais adequadas para o aluno, por mais que os profesores das escolas se esforcem para dar atendimentos de modo individualizado é inviável atender desta forma. Assim, as aulas particulares podem fornecer este apoio de aprendizado exclusivo, como o professor particular esta ali para ajudar somente aquele aluno. Ele pode parar e explicar novamente, se dedicar somente a sanar dúvidas daquele aluno, especialmente na alfabetização que se demanda mais tempo individualizado, pois cada aluno tem seu ritmo para se alfabetizar.

A adaptação escolar em tempo de pandemia não foi uma tarefa fácil. A internet que não ajudou, situação financeira não favorável no momento para a compra de um computador, tarefas acumuladas, convivência virtual, dentre outras dificuldades que são relatadas pelos pais. Uma saida encontrada pelos mesmos foi a das aulas particulares/ reforço escolar, que pode ocorrer em determinados días da semana, em horários inversos ao das aulas remotas, por uma hora.

Além das aulas particulares serem um apoio ao ensino, também se tornou uma saída profissional para muitos professores. 


\section{As aulas na prática}

Logo que me formei em Pedagogia, comecei a dar aulas particulares, uma aqui, outra ali, muito raramente. Logo depois do ínicio da pandemia a procura foi maior, como não conseguia dar conta de todos os horários, minha mãe, que também é pedagoga começou a dar aulas também, porém a procura continuava maior e nosso espaço não era tão organizado para receber as crianças, então começamos a investir, tanto no material como organização e divulgação.

Logo, de uma sala de nossa casa, fizemos uma sala de aula, com quadro branco, alfabeto na parede, jogos pedagógicos, máscara, álcool gel e todo material necessário para atender os pequenos. Assim começamos... as pessoas conhecidas logo souberam do trabalho e para nossa surpresa teve uma procura muito grande, não podendo atender á todos infelizmente.

As aulas são ministradas em duração de uma hora aula por aluno, somente um aluno por vez, com intervalo de $30 \mathrm{~min}$ para fazer a higienização da sala como pede o protocolo, higienização com álcool da mesa, cadeira, piso e materiais concretos que utilizamos na aula anterior. A procura dos pais por aula particular não foi só pela preocupação de seus filhos não se alfabetizarem, mas também o acumulo de material para as crianças fazerem e os mesmos não terem tempo para ajuda-los. Vimos nos olhos de pais preocupados, o medo de seu filho ficar para trás, medo de uma criança não conseguir se alfabetizar nesse novo modelo de ensino e avançar o ano com dificuldades.

Antes de montarmos essa sala para atender nossos alunos, pensamos sempre em manter o aluno mais próximo da realidade escolar, nunca tirando a importância da escola e da professora regente, pois afinal somos uma equipe com o propósito de auxiliar nosso aluno(a) na aprendizagem. Então como somos Pedagogas e Neuropsicopedagogas decidimos investir não só na parte "Alfabetização", mas sim tornar o momento lúdico, agradável, que o aluno sinta vontade de voltar e aprender cada vez mais, dessa forma além de materiais que visam a alfabetização com embasamento em autores da pedagogia, também utilizamos a tecnologia e jogos diversos a nosso favor, mantendo o aluno sempre no meio lúdico. Dessa forma aprender fica divertido, e a variedade de recursos instiga a aprendizagem, segundo Guerra (2021):

Adequar o aprendizado significa ter o foco na aprendizagem do que é mais importante, desenvolver as habilidades socioemocionais previstas na BNCC, reorganizar conteúdos de acordo com a nova realidade educacional, rever e adaptar objetivos. Avaliar e criar estratégias de recuperação da aprendizagem, disponibilizar meios tecnológicos e outros recursos de complementação da aprendizagem. ( GUERRA, 2021).

Dessa forma, de acordo com a realidade, ritmo e dificuldades do aluno, escolhemos os recursos que iremos utilizar durante as aulas, nossos alunos estão em fase de pré-alfabetização e alfabetização. Os horários são organizados de forma que o aluno participe das aulas em período inverso a sua aula remota, pois assim não fica cansativo, e o mesmo pode nos trazer dúvidas que tenha tido em aula, 
dessa forma vamos fazendo o acompanhamento e tendo avanços na aprendizagem, aulas particulares $\mathrm{x}$ familia $\mathrm{x}$ professora regente $\mathrm{x}$ escola, todos por um bem em comum.

Não utilizamos somente um meio de ensino, pois cada aluno tem um jeito de aprender, também não se pode falar em "método", mas sim em um conjunto de procedimentos para garantir a aprendizagem, e em aulas particulares não se pode ser diferente. Segundo Freira (1996), "ensinar não é transferir conhecimento, mas criar as posibilidades para a sua produção ou a sua construção". Neste reforço são feitas atividades diferenciadas que envolvem nossos alunos de forma participativa, ajudando a vencer os obstáculos presentes em sua aprendizagem.

Saviani (2000) afirma que o caminho do conhecimento:

É perguntar dentro da cotidianidade do aluno e na sua cultura; mais que ensinar e aprender um conhecimento, é preciso concretizá-lo no cotidiano, questionando, respondendo, avaliando, num trabalho desenvolvido por grupos e individuos que constroem o seu mundo e o fazem por si mesmos. (SAVIANI, 2000, p. 41).

A partir disso, buscamos instrumentos para expor o conteúdo de diversas maneiras, de acordo com a realidade do seu aluno, até que o mesmo aprenda. Portanto as atividades do reforço devem trazer ao aluno o interesse para aprender. Dentre o conjunto de procedimentos que utilizamos em nossas aulas para a pré- alfabetização e alfabetização, podemos citar: método alfabético, método silábico, método fonovisuoarticulatório, recursos didáticos, jogos pedagógicos e lúdicos.

Método Alfabético: este é o método mais comum que utilizamos. A criança aprende primeiro o nome das letras do alfabeto para, em um segundo momento, fazer as combinações silábicas e assim montar as palavras (Figura 1).

Figura 1: Atividades de pareamento das letras do alfabeto, lince e nome próprio

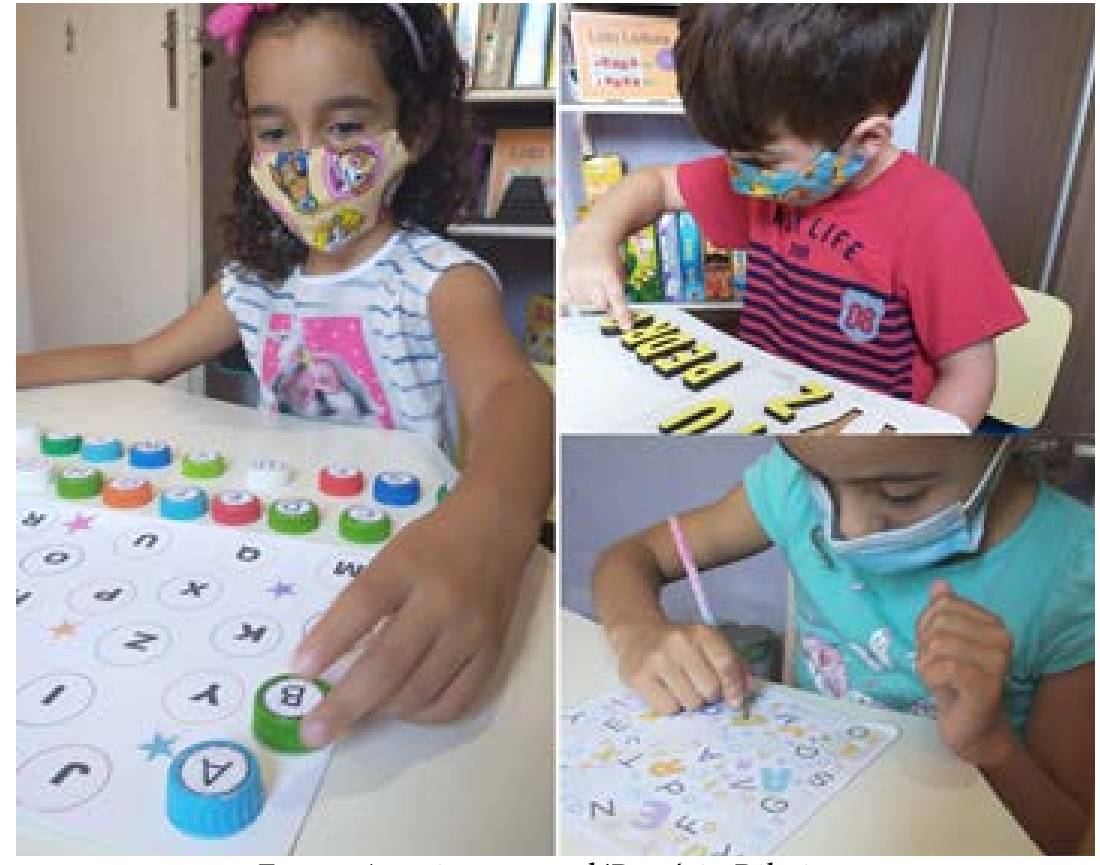

Fonte: Arquivo pessoal/Patrícia Ribeiro. 
Método Silábico: neste, a criança aprende as familias das silabas antes de formar/compreender as palavras (Figura 2).

Figura 2: Alunos fazendo atividades com as silabas e suas junções

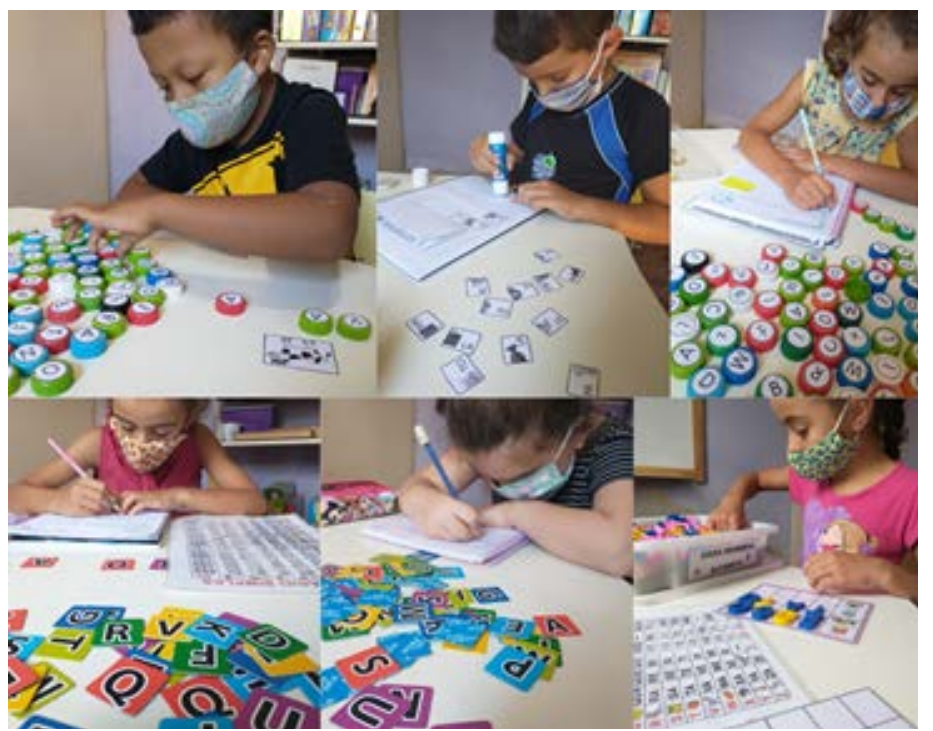

Fonte: Arquivo pessoal/Maria Helena Silva.

Método Fonovisuoarticulatório: conhecido como método "boquinhas", utiliza-se de estratégias fônicas (fonema/som), visuais (grafema/letra) e as articulatórias (articulema/boquinas). Segundo Jardini, o método é alicerçado “[...] na fonoaudiología, em parceria com a Pedagogia, que o sustenta, sendo indicado para alfabetizar quaisquer crianças e mediar/ reabiliatar as dificuldades da leitura e escrita. O método viabiliza e favorece a alfabetização [...]”.

Utilizamos este método especialmente na apresentação da vogais (Figura 3), pois os alunos gostam de fazer bem a articulação da boca quando oralmente dizem a letra que se é pedida. Desta forma, vimos que os mesmos não esquecem da forma como é falada a letra e o som que sai da boca.

Figura 3: Atividade das vogais com o método boquinas

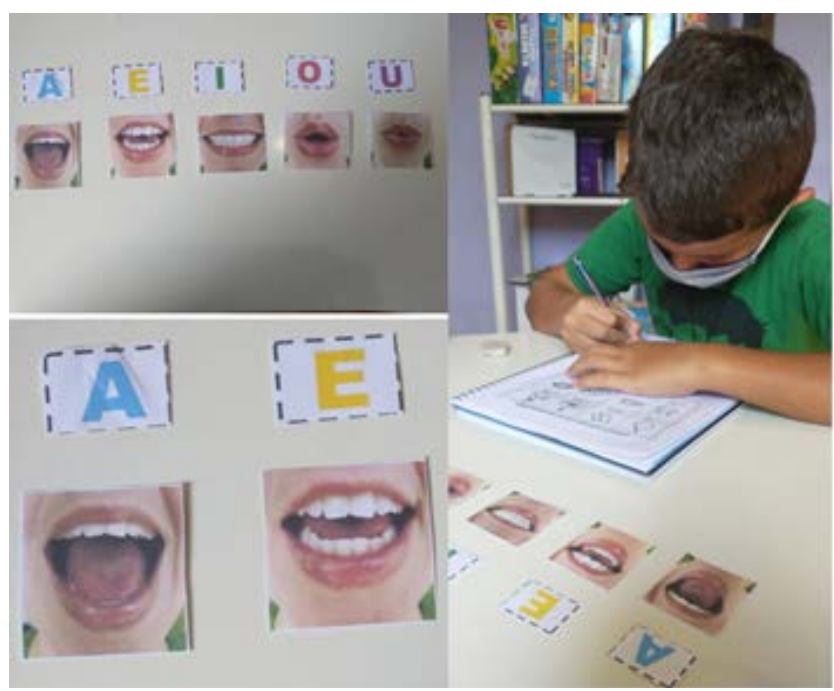

Fonte: Arquivo pessoal/Patrícia Ribeiro. 
Recursos Didáticos: os recursos didáticos são todas aquelas ferramentas que auxiliam o professor no proceso de ensino-aprendizagem, facilitando a compreensão do aluno acerca do tema abordado. Existe uma grande variedade de recursos disponibilizados para o ensino, que vão desde os recursos mais simples aos mais avançados e tecnológicos (Figura 4), basta saber a realidade do aluno para utilizar. Na nossa sala, utilizamos recursos variados. Souza (2007, p. 112-113) destaca:

Utilizar recursos didáticos no proceso de ensino-aprendizagem é importante para que o aluno assimili o conteúdo trabalhado, desenvolvendo sua criatividade, coordenação motora e habilidade de manusear objetos diversos que poderão ser utilizados pelo professor na aplicação de suas aulas. (SOUZA, 2007, p. 112-113).

O uso destes recursos possibilita dinamizar a aula, além de establecer um vinculo a mais do aluno com o conteudo trabalhado (Figura 5).

Figura 4: Alunos no notebook com atividades de junção de sílabas

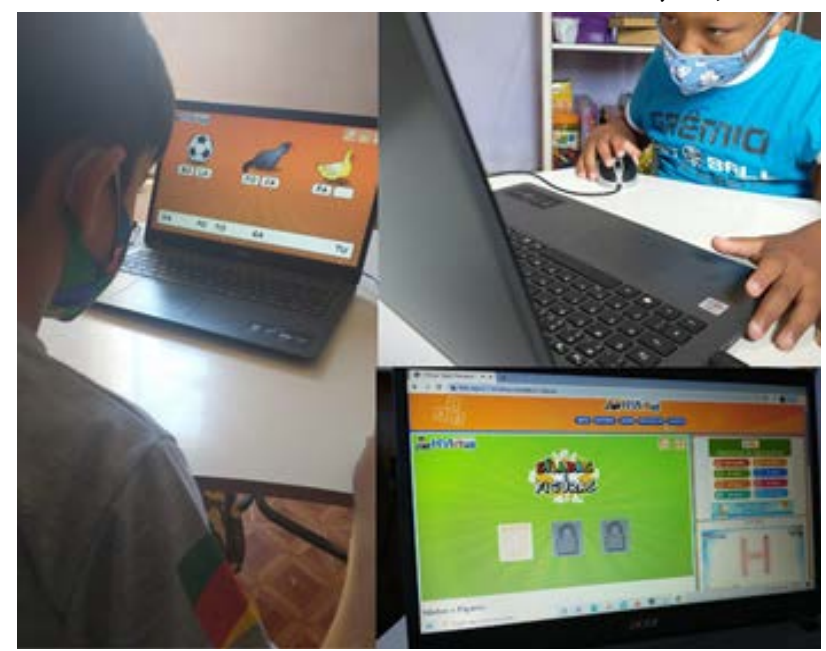

Fonte: Arquivo pessoal/Maria Helena Silva.

Figura 5: Recursos utilizados durante as aulas

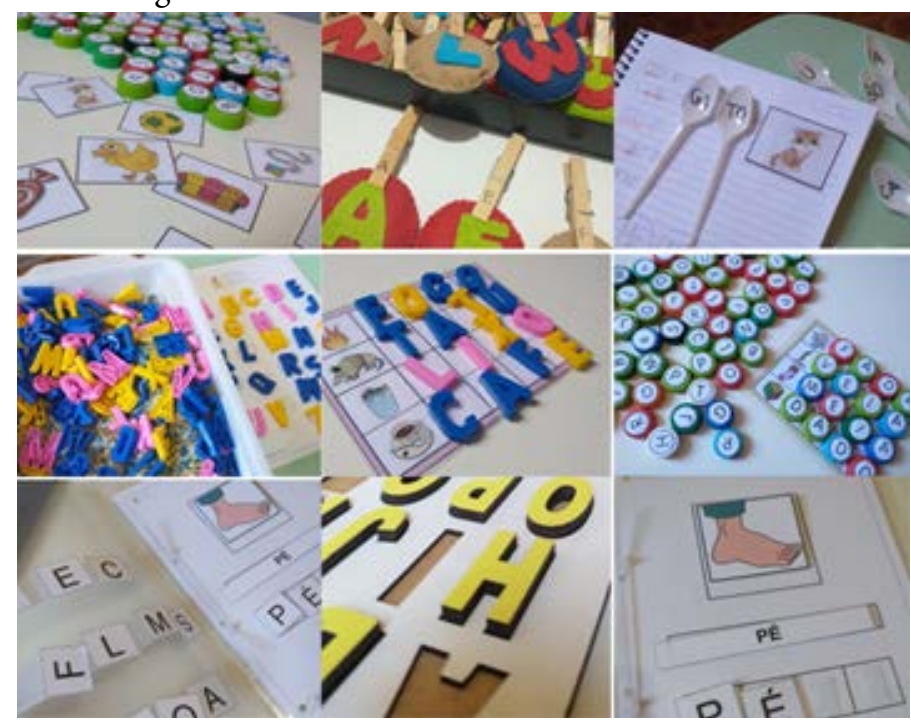

Fonte: Arquivo pessoal/Patricia Ribeiro. 
Jogos Pedagógicos e Lùdicos: Segundo Lopes (2001, p. 35-36), “os beneficios do jogo já são conhecidos, porém, é importante que o educador, ao utilizar o jogo tenha definidos objetivos a alcançar e saiba escolher o jogo adequado ao momento educativo". O ato de jogar prepara a criança para vida adulta, pois ela desenvolve suas potencialidades, e sente-se segura. O educador debe definir seus objetivos e escolher o jogo adequado para utilizar naquele momento.

O jogo é um ótimo recurso didático ou estratégia de ensino para nós educadores e também ser um rico instrumento para a construção do conhecimento. Jogos didáticos podem facilitar o proceso de ensino-aprendizagem e ainda serem interesantes e desafiantes.

Lara (2004, p. 23) afirma:

\begin{abstract}
Que os jogos, últimamente, vêm ganando espaço dentro das escolas numa tentativa de trazer o lúdico para dentro da sala de aula. Acrescenta que a pretensão da maioria dos profesores com a sua utilização é a de tornar as aulas mais agradáveis com o intuito de fazer com que a aprendizagem torne-se algo mais fascinante, além disso, as atividades lúdicas podem ser consideradas como uma estratégia que estimula o raciocinio, levando o aluno a enfrentar situações conflitantes relacionadas com o seu cotidiano.
\end{abstract}

Durante nossas aulas, sempre colocamos no plano dois jogos (Figura 6 e 7). Um mais didático, de acordo com o que estamos trabalhando, e outro mais lúdico, para a criança ter um momento de brincar. As mesmas nos contam que neste modelo remoto, elas não tem contato físico com os colegas para poder ter essa interação. Dessa forma, nós tentamos suprir este momento utilizando esses jogos na sala e tendo essa interação com eles.

O jogo contribui para a socialização no ambiente de sala de aula, a medida que os alunos vão interagindo, desenvolvem-se laços afetivos, e é por este motivo que utilizamos os mesmos na nossa sala, pois criamos um vínculo muito grande com nossos alunos, facilitando assim a aprendizagem deles.

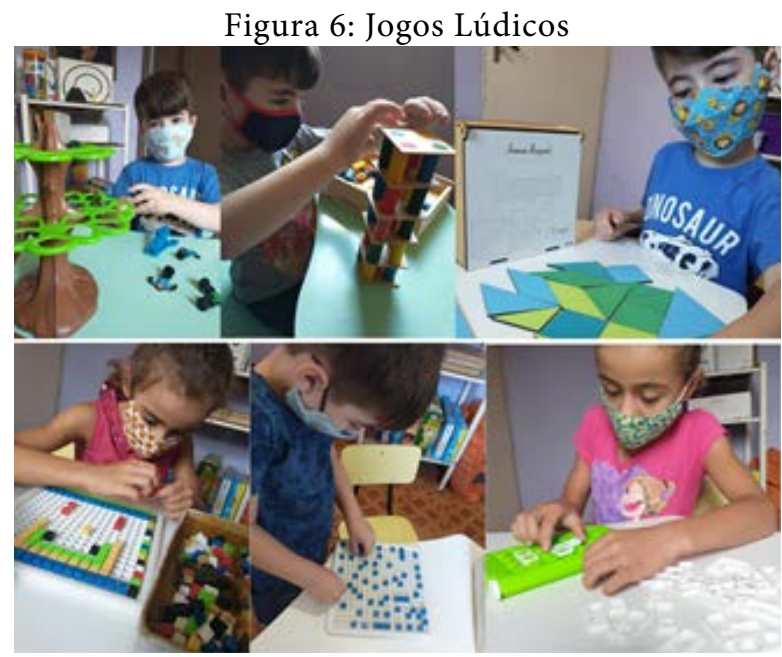

Fonte: Arquivo pessoal/Patricia Ribeiro. 
Figura 7: Jogos Pedagógicos

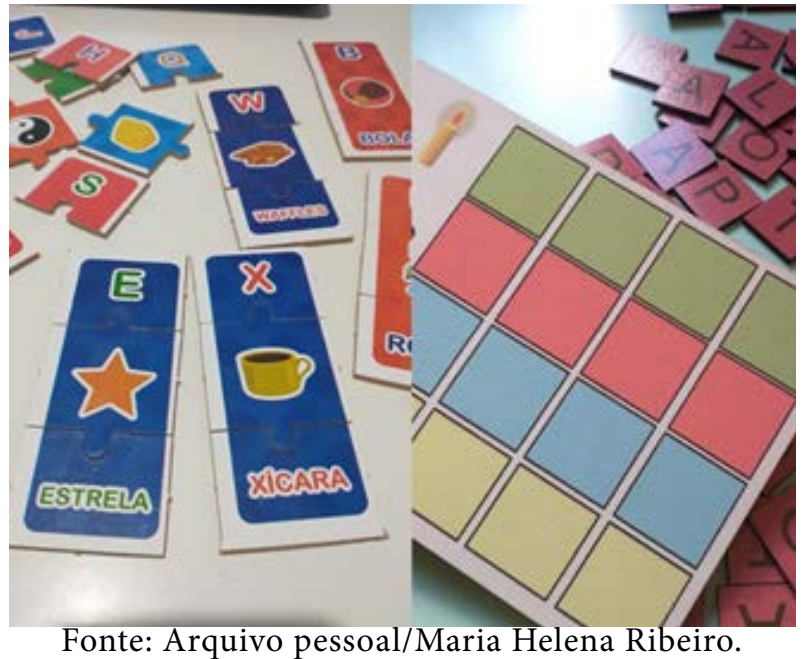

\section{Considerações finais}

Neste capítulo, relatamos como nossas aulas particulares em tempo de pandemia estão acontecendo e qual a sua importância na vida tanto do aluno quanto da família nesse novo normal que estamos vivenciando. Aulas online, atividades enviadas pelo Whatsapp, falta de tempo dos pais para darem apoio aos seus filhos e assim por diante. As dificuldades são muitas, mas a procura por aulas particulares foi grande e assim apresentamos aqui como nosso trabalho é desenvolvido nesse momento.

O retorno dos pais é satisfatório. Assim, percebemos que estamos ajudando na aprendizagem do aluno e que o mesmo está chegando à alfabetização e esta em constante progresso. Hoje, contamos com 10 alunos e alguns na lista de espera, tanto para alfabetização quanto só para o acompanhamento do ano letivo. Utilizamos para divulgação das aulas particulares uma página no facebook, onde relatamos nossas aulas tanto em textos quanto fotos.

Esperamos que as aulas voltem ao normal o quanto antes, pois sabemos da importância das mesmas, a importância do professor em sala de aula e a convivência dos alunos com seus colegas, mas no momento priorizamos a saúde, pois o Covid-19 é um vírus que precisamos ter cuidados. Enquanto isso não acontecer, nós como professoras particulares seguimos com nossas aulas, ajudando a quem nos procura com profissionalismo, procurando sempre o melhor para nosso aluno e acima de tudo dar carinho e muito afeto, pois gostamos da nossa profissão e a nossa recompensa são alunos e pais satisfeitos.

Relatos de alunos como "ainda bem que tem essa aula, tia, porque só no computador é difícil. Aqui, a gente aprende, brinca e se diverte muito. Vou pedir para minha mãe para vir mais vezes". Ouvindo esse aluno, ficamos felizes pois estamos conseguindo aplicar o que pensamos logo no ínicio: proporcionar aos nossos aluno uma aula mais próximo possivel da realidade escolar, com materiais diversos, dinâmicos, prazerosos e conseguir tornar esse estilo remoto um pouco menos cansativo para os mesmos, lembrando que as aulas particulares não suprem a necessidade da aula presencial e sim somos um apoio a mais. 


\section{Referências}

FREIRE, Paulo. Pedagogia da autonomia: saberes necessários à prática educativa. São Paulo : Paz e Terra, 1996.

LARA, Isabel Cristina Machado de. Jogando com a matemática $5^{\circ}$ e $8^{\circ}$ série. São Paulo: Rêspel, 2004.

LOPES, Maria da Glória. Jogos na educação: criar, fazer, jogar. 4 ed. São Paulo: Cortez, 2001.

SAVIANI, D. Saber escolar, currículo e didática. 3 ed. Campinas: Autores Associados, 2000.

GUERRA, Gleidis. Um novo normal também na escola. Aventura de construir, 2021. Disponível em: $<$ https://aventuradeconstruir.org.br/8936/>. Acesso em: $1^{\circ}$ mar. 2021.

JARDINI, Renata Savastano Ribeiro. Método boquinhas: fundamentação teórica. Metodo das boquinhas, 2018. Dísponivel em: <https://metododasboquinhas.com.br/fundamentacao-teorica/>. Acesso em: 13 mar. 2021.

SANTOS, M. C. A importância da produção de material didático na prática docente. In: CONGRESSO BRASILEIRO DE GEÓGRAFOS, 7, Vitória, 2014. Vitoria/ES. Anais do VII CBG. Disponível em: <http://www.cbg2014.agb.org.br/resources/anais/1/1404098564_ARQUIVO_ AImportanciadaProducaodeMaterialDidaticonaPraticaDocente.pdf $>$. Acesso em: 10 mar. 2021. 
